\title{
ORIXÁS SÃO SUPER-HERÓIS: MEDIAÇÕES DOS QUADRINHOS NO CONTEXTO DA EDUCAÇÃO INTERCULTURAL
}

Robéria Nádia Araújo Nascimento ${ }^{(*)}$

\section{INÍCIO DE CONVERSA}

Como as diferenças religiosas inerentes ao pluralismo de crenças são tratadas na escola? De que modo a organização curricular, as práticas de ensino e o conhecimento escolar contemplam a discussão da diversidade religiosa? As configurações das religiões afro-brasileiras, que aqui nos interessam de modo particular, se imbricam a questões sociais, culturais e históricas. Tal cruzamento atravessa os protocolos do ensino religioso como também permeia os saberes históricos. Entendemos que, numa sociedade multidiversa, o enfoque dessas religiões transcende as demarcações curriculares e aponta a necessidade de uma escola menos fragmentada, cuja docência é desafiada para a construção de conhecimentos significativos e aprendizagens relevantes que assegurem a voz e a presença do outro na sala de aula.

Nessa direção, o recorte do presente texto explora as discriminações que afetam as crenças de matriz africana no espaço social e que, consequentemente, reverberam no universo escolar. Uma análise superficial de alguns livros didáticos de história já permite a observação de que os indígenas ainda são mostrados como seres exóticos, atrasados ou ariscos, enquanto os africanos são tratados pela ótica da submissão. Não há aprofundamentos acerca da capacidade de resiliência do povo negro ou sobre suas crenças ancestrais, embora a história cultural africana aglutine esses aspectos. Do ponto de vista do ensino religioso, os materiais e métodos referenciam as religiões majoritárias. Partimos dessas constatações para pensar o silenciamento das religiões de matriz africana na educação, estabelecendo elos entre saberes e áreas a fim de propor um diálogo com as diferenças e singularidades dos grupos invisibilizados.

O fluxo das fronteiras disciplinares é alicerçado no paradigma da interculturalidade, que permite à educação reconhecer especificidades e similaridades dos grupos sócio-históricos rompendo com a perspectiva cultural homogeneizante que os define. A vertente parte do pressuposto de que somos unos e múltiplos em nossas diferenças. Vivemos num mundo no qual as culturas e os sujeitos históricos enfrentam questões multiétnicas, por isso o ensino-aprendizagem da

\footnotetext{
${ }^{(*)}$ Doutora em Educação (UFPB). Professora do Programa de Pós-graduação em Formação de Professores (PPGFP/UEPB). Professora associada da UEPB. E-mail: rnadia@terra.com.br.
} 
diversidade histórico-religiosa pode contribuir para a compreensão da alteridade nos espaços educativos, a fim de embasar uma convivência sociocultural democrática, ancorada no reconhecimento e no respeito das diferentes expressões de fé existentes na sociedade.

As crenças de matriz africana são regidas por deuses denominados de orixás, mas a alusão às divindades não ocorre nas salas de aula, como se este assunto fosse restrito aos adeptos. A postura de negação vigente no espaço escolar respalda a invisibilidade e confirma a predominância dos credos majoritários (catolicismo e protestantismo), sem abordagem das demais crenças, cujos praticantes também frequentam os espaços escolares, mas são inferiorizados e relegados ao silenciamento.

Nesse cenário, crianças e adolescentes da educação fundamental desconhecem os arquétipos e os sentidos dos mitos sagrados de tais religiões, e, por extensão, não valorizam as tradições ancestrais da cultura negra, nem tampouco reconhecem suas influências na formação da sociedade brasileira. Cabe, portanto, trabalhar em prol de uma escola sem estigmas que forme para a compreensão da diversidade como condição de cidadania.

Em face disso, argumentamos a favor de estratégias lúdicas para o tratamento dessas questões, sugerindo a adoção dos quadrinhos em sala de aula, de modo a favorecer intercâmbios entre educação, história e religiosidades para além das demarcações curriculares. Nesse sentido, a coletânea de HQs "Contos dos Orixás" é indicada como recurso didático-pedagógico. Narrativas produzidas pelo desenhista Hugo Canuto transformam as divindades africanas em super-heróis. A junção do lúdico com informações históricas pode viabilizar experiências positivas de aprendizagem e, ao mesmo tempo, mobilizadoras da superação dos preconceitos em torno das crenças afro-brasileiras. Defendemos a premissa de que o público infanto-juvenil tende a ser cativado pelas sagas de super-heróis e suas aventuras, que podem traduzir saberes importantes, sob uma mediação pedagógica intercultural.

O argumento é fundamentado em três eixos: o primeiro destaca as balizas da interculturalidade com foco nas potencialidades docentes para a sua materialização educativa. $\mathrm{O}$ segundo propõe pistas para o ensino das crenças de matriz africana com ênfase na alteridade étnicoracial. O terceiro eixo apresenta as especificidades da coletânea de $\mathrm{HQs}^{1}$ e sistematiza procedimentos metodológicos para a sua utilização no Ensino Fundamental.

\footnotetext{
${ }^{1}$ O quadrinista e ilustrador Marcelo D' Salete também produz significativa obra em quadrin hos que narra a constituição dos quilombos reconstituindo a história do período colonial brasileiro para discutir as estruturas do racismo. Destacamse os livros "Cumbe" (2014) e "Angola Janga" (2017).
} 


\section{RELIGIOSIDADES AFRO-BRASILEIRAS NAS TRILHAS DE UMA EDUCAÇÃO INTERCULTURAL}

A compreensão da interculturalidade passa pela concepção de identidade que, como explica Hall (2004), constitui um produto das experiências culturalmente compartilhadas e das negociações de sentidos sociais. Os sistemas coletivos de representação também (re)criam as diferenças transformando os modos de percepção de si dos indivíduos nas trocas simbólicas do tecido cultural. A discussão daí derivada interessa à educação e a seus processos, porque a escola promove o aprendizado da alteridade por ser um espaço de identidades plurais "para nós e os outros".

Fleury (2003) explicita que a noção de intercultura salienta a possibilidade de respeitar as diferenças e de integrá-las numa unidade que não as anule. O conceito alude, portanto, à criação de atalhos compreensivos do "lugar do outro" na sociedade. Na educação, formata um paradigma interdisciplinar e transversal, no sentido de tematizar e teorizar a complexidade (para além da pluralidade ou da diversidade) e a ambivalência ou o hibridismo (para além da reciprocidade ou da evolução linear) na construção do conhecimento. Consequentemente, são reconhecidas relações intergrupais e intersubjetivas de campos identitários como etnias, gerações, religiosidades ou gêneros.

A constatação das diferentes subjetividades que permeiam o mundo social tem inspirado iniciativas pedagógicas para a renovação metodológica, acenando para epistemologias de compreensão e promoção do diálogo entre culturas. O ensino e as aprendizagens são pensados para além das demarcações disciplinares valorizando as diferenças que estruturam "o outro". Desse modo, novos formatos curriculares são traçados para a valorização das culturas subalternas e excluídas. Com essa finalidade, o trabalho intercultural em sala de aula "pretende construir uma disponibilidade para a leitura positiva da pluralidade social de um novo ponto de vista baseado no respeito às diferenças” (FLEURY, 2003, p. 5).

Contudo, o autor observa que a escola ainda é apontada pelos estudantes e professores como um território de situações discriminatórias, um ambiente de enfrentamentos "invisíveis", onde, num paradoxo, as diferenças são marcadas por aspectos "visíveis", a exemplo da deficiência física, do vestuário (indicador de pertencimento a uma classe social), das práticas religiosas, da orientação sexual e da cor da pele. No enfrentamento dessas tensões, a educação intercultural potencializa a própria ação desencadeada nos conflitos "mediante o diálogo e o encontro, de modo que a escola forje espaços produtores de outras formas de identidades marcadas pela fluidez, pela interação e pela acolhida do diferente" (FLEURY, 2003, p. 7). 
Aires (2013) assinala que um dos embates corresponde aos estereótipos e opiniões estigmatizadas sobre a religiosidade afro-brasileira e suas reinterpretações que circulam na sala de aula, pois "desde cedo construímos representações dos africanos como seres selvagens em detrimento do parâmetro positivado instituído pelos currículos ocidentalmente europeizantes" (AIRES, 2013, p. 26).

Para romper com esse paradigma, os docentes precisam entender o currículo como dispositivo educacional ideológico ligado a seleções e interesses, através do qual a escola realiza operações de inclusões e exclusões temáticas. Cabe, portanto, a esses profissionais alinhar as diretrizes com as demandas históricas selecionando conteúdos relevantes que "descolonizem" o currículo para viabilizar a diversidade cultural e o respeito às diferenças em sala de aula e para além dela.

Uma postura nesses moldes envolve a inclusão no espaço escolar das identidades étnicas a partir de conhecimentos sobre história, culturas, religião e linguagem como constituintes de cada grupo em seus fatores de pertencimento, sociabilidade e coesão: a religião, por exemplo, é um campo de matriz interdisciplinar, constituindo-se num significativo elemento identitário dos grupos ao permitir a afirmação de suas culturas históricas.

\section{AS PRÁTICAS AFRO-BRASILEIRAS: ENFOQUES PARCIAIS NOS AMBIENTES EDUCATIVOS}

As religiões de matriz africana, embora configurem fontes de herança cultural do país, continuam sendo perseguidas em nome da fé cristã: " $O$ discurso religioso católico em torno da salvação foi o arcabouço ideológico utilizado para justificar a conquista e a colonização, legitimando a violência física e simbólica" (AIRES, 2013, p. 27). Constantemente alvos de demonização $^{2}$, seus adeptos sofrem acusações racistas, num horizonte que empobrece o debate das alteridades religiosas por desconhecer as heterogeneidades de outros credos.

Oliveira (2011) relata que, mesmo nos dias de hoje, "o povo dos terreiros ainda enfrenta a repressão, sendo apontado como adorador do mal, cujas práticas de fé são, no mínimo, associadas ao exótico ou ao folclore" (OLIVEIRA, 2011, p. 124). Por essa razão, os praticantes das cosmologias africanas são tratados como seres atrasados e supersticiosos na sociedade, forjando uma visão negativa que alcança a escola e seus agentes.

\footnotetext{
2 Oliveira (2011) menciona a obra do Bispo Edir Macedo: Orixás, caboclos e guias: deuses ou demônios? lançada em 1995. No livro, as divindades afro-brasileiras e as demais religiões espiritualistas são mostradas como cultos satânicos e denominadas de "seitas demoníacas".
} 
Para Silva (2010) há poucos documentos históricos que legitimam essas religiosidades, o que contribui para o enraizamento do preconceito. As narrativas religiosas são contadas de modo anônimo no interior dos inúmeros terreiros fundados pelos descendentes africanos. Entretanto, aos olhos da população e de muitos intelectuais, suas trajetórias não possuem a relevância do catolicismo, "cuja história permeia os livros didáticos e é disseminada nos currículos escolares como matéria principal do ensino religioso facultativo" (SILVA, 2010, p. 94).

Esta literatura não mostra que o desenvolvimento do candomble ${ }^{3}$ foi marcado, entre outros fatores, pela reelaboração da identidade social e religiosa dos grupos negros, durante as condições adversas da escravização e, posteriormente, nas situações de desamparo social: "a história das religiões afro-brasileiras faz ecoar no plano religioso as imposições, contradições e aproximações existentes nas relações sociais entre negros, brancos e índios" (SILVA, 2010, p. 96).

É inconcebível que palavras como "orixás" ou "pais de santo" não sejam pronunciadas em alguns ambientes educativos como se fossem proibidas por um suposto teor "pecaminoso". Constatamos tal impressão ao socializarmos uma pesquisa acadêmica sobre candomblé e ficção numa escola católica do estado da Paraíba. Crianças do $5^{\circ}$ ao $8^{\circ}$ ano do Ensino Fundamental participaram da exposição, referente à adaptação televisiva de "Tenda dos Milagres", inspirada na obra de Jorge Amado ${ }^{4}$ (a semana era dedicada ao estudo de escritores nordestinos).

Para ilustrar as diferentes retaliações sobre o candomblé e seus adeptos, motivadas pela intolerância religiosa, exibimos trechos da minissérie (que retrata a perseguição aos terreiros e aos adeptos na década de 1930), além de videorreportagens contemporâneas sobre incêndios criminosos nos terreiros, com agressões físicas aos praticantes, em relatos de apedrejamento. A intenção era problematizar uma forma de violência iniciada no passado colonial brasileiro, mas que ainda continua ativa no presente. Porém, as turmas do $5^{\circ}$ ano se incomodaram com a "expressão terreiros" e pareceram indiferentes às violações aos espaços sagrados do candomblé.

Enquanto a maioria ignorava as dimensões do problema, uma das alunas, talvez a mais "corajosa" da sua turma, disse que, para ela, "terreiro" significava "um cercado para galinhas". Professoras, supervisoras e as turmas riram dessa analogia. Em tom de desaprovação a essa postura,

\footnotetext{
${ }^{3}$ Junção do termo quimbundo candombe (dança com atabaques) derivada do Iorubá ilé ou ilê (casa), significando "casa de dança com atabaques". Cultua os Orixás que são considerados divindades da natureza, através de danças, oferendas e sacrifícios. Já a Umbanda é uma religião brasileira que sintetiza elementos de crenças africanas e cristãs, reunindo tradições de movimentos religiosos como o candomblé, o catolicis mo e o es piritismo.

${ }^{4} \mathrm{O}$ escritor era $O g a \tilde{a}$, um praticante da religião responsável pelo toque dos tambores nas celebrações dos terreiros. $\mathrm{O}$ título homenageia pessoas que prestam serviços relevantes à comunidade do candomblé.
} 
perguntamos se nas aulas de religião ou de história não havia referências às crenças de matriz africana ou a seus símbolos e lugares sagrados. A plateia silenciou, e a menina quis saber, dessa vez, o que era "religião de matriz africana". Ao entender o sentido, sorriu com simpatia e declarou que "nunca tinha ouvido falar em terreiro", pois a informação não constava nos livros didáticos das disciplinas mencionadas (religião e/ou história), e que nem mesmo a professora de religião, ausente naquela oportunidade, havia se referido ao tema. O episódio revela que nas escolas de ensino confessional a religiosidade afro-brasileira permanece um tabu.

Vinagre Silva (2007) especifica que os terreiros são territórios sagrados e de pertencimento que valorizam e preservam a identidade cultural dos filhos de santo, uma vez que produzem a reafirmação étnica e a socialização da fé nas divindades africanas, que ali se manifestam para a proteção dos adeptos. São espaços de inclusão, pois aglutinam indivíduos discriminados socialmente para o exercício legítimo de suas religiosidades mestiças: negros/não-negros, homens/mulheres/crianças, indivíduos de diferentes orientações sexuais e pertencentes a distintas classes, até mesmo os portadores de deficiência e de comprometimento mental, que não são aceitos em outras práticas religiosas. Portanto, não são lugares de "negros"; são lugares de todos/as.

O vocábulo se reporta ao período pós-abolição, representando aldeias humildes, erguidas em chão batido, para atividades pastoris de sobrevivência, localizadas nas periferias urbanas. Hoje, os terreiros permeiam diversos bairros, em construções de alvenaria, mas muitos ainda se mantêm incógnitos misturando-se à arquitetura das ruas por temor à violência. Em síntese, é um espaço de culto democrático onde os segmentos subalternizados da sociedade "podem experimentar a possibilidade de ascensão social e de desenvolvimento de uma nova sociabilidade, metamorfoseando seus lugares de desvantagem social com posições de prestígio na hierarquia religiosa" (VINAGRE SILVA, 2007, p. 6).

De acordo com Oliveira (2011) a cosmologia ancestral africana possibilita a compreensão do ethos cultural brasileiro. Nessa perspectiva, a tríade educação, religiosidade e história pode mostrar que negros e índios não são peças imóveis do mosaico social. Dessa forma, os currículos escolares precisam considerar e notabilizar as trajetórias dessas populações dirigindo um olhar para as sensibilidades de suas crenças culturais e religiosas a fim de combater a discriminação.

Num relevante estudo sobre a educação das crianças candomblecistas, Caputo (2016) detectou que a religião continua sendo ignorada nas escolas, onde os filhos de santo são discriminados pelo estigma de "macumbeiros". Alguns deles até se dizem católicos para fugir dos preconceitos. A autora realizou entrevistas com 14 professores do Ensino Fundamental numa escola 
da Baixada Fluminense. Desses, nove responderam que desconheciam a presença de candomblecistas no ambiente escolar. Uma das professoras chegou a afirmar: "não temos crianças com esse 'problema'. A maioria é católica".

Cinco dos entrevistados acham "um absurdo ter crianças do candomblé, pois crianças não devem ser induzidas à macumba só porque os pais frequentam”. A pesquisadora, então, questionou "se os pais católicos também não estariam induzindo seus filhos ao catolicismo quando os batizavam, os levavam às missas, colocavam no catecismo". A docente tentou se defender: "Mas o catolicismo não é coisa do diabo, é a religião normal!” (CAPUTO, 2016, p. 173).

Desse modo, os adeptos escondem seus pertencimentos, e a religião de matriz africana é invisibilizada a partir de tentativas para homogeneizar as crenças e evitar rejeições: "Crianças e jovens do candomblé estão na escola, mas escondem seus orixás debaixo dos uniformes" (CAPUTO, 2016, p. 178). Segundo a autora, são crianças discriminadas pelos professores como se fossem "problemas" a procura de soluções.

Nas palavras de Candau (2011), a cultura escolar dominante em nossas instituições educativas "prioriza o comum, o uniforme, o homogêneo, considerados como elementos constitutivos do universal. Nesta ótica, as diferenças são ignoradas ou consideradas um "problema" a resolver" (CANDAU, 2011, p. 241). O reconhecimento e a valorização das diferenças sóciohistóricas não são prioridades dos currículos, o que gera tensionamentos e exclusões. O grande desafio educacional tem sido reconhecê-las positivamente em suas marcas identitárias, para que não se tornem objeto naturalizado de preconceito e discriminação.

Aires (2013) considera que a criminalização do racismo e a obrigatoriedade imposta pela Lei 10639, que determinou os conhecimentos da cultura negra na escola, ainda são passos lentos na criação de uma cidadania cultural para as religiões afro-brasileiras. No seu entender, a violência contra os cultos é física e simbólica: a espada do colonizador é atualizada através das perseguições aos terreiros; a cruz do missionário também se replica no discurso preconceituoso das igrejas cristãs; a caneta da lei ainda gasta alguma tinta na tentativa de deslegitimar as religiosidades marginais. Resta desenvolver um trabalho educativo de conscientização para que "o livro da escola nos aponte outras direções trazendo novas lições na contramão da história” (AIRES, 2013, p. 57). 


\section{A SIMBOLOGIA DOS QUADRINHOS A FAVOR DA RELIGIOSIDADE AFRO- BRASILEIRA}

Do ponto de vista metodológico, o enfoque das religiões afro-brasileiras na escola precisa ressaltar a historicidade do continente africano em consonância a uma reflexão sobre a formação identitária do povo brasileiro. Assim, conhecimentos sobre a diáspora tornam-se essenciais à compreensão dos processos de construção das identidades étnicas para criar um cenário favorável à valorização da população negra e de suas expressões culturais.

Dadas essas condições, a interculturalidade, como proposta teórica, pode fundamentar práticas pedagógicas que situam os sujeitos da educação como atores históricos em dinâmicas de reconhecimento de suas vozes e trajetórias. Para operacionalizar essa perspectiva, o processo pedagógico deve interpelar professores e alunos sobre suas identidades dentro e fora dos ambientes escolares. Algumas questões podem orientar esse diálogo: Como os sujeitos traduzem suas expressões culturais? Como a religiosidade pode propiciar os pertencimentos identitários e as dinâmicas de reconhecimentos? Como os diferentes grupos, que educam e se educam, criam suas culturas religiosas? Quais são elas? Por que a intolerância religiosa ainda precisa ser discutida nos ambientes escolares?

Para enriquecer o debate, Melo (2013) propõe a desconstrução de conceitos que foram ressemantizados na escola e nos livros didáticos. Nas sessões onde se lê "castigo" aos negros, as obras, na verdade, produzem eufemismos que omitem torturas e não as relatam. As menções à "escravidão" também são inadequadas, pois não se nasce escravo. O correto seria discutir "a escravização" dos seres humanos. A afrocentricidade é, portanto, um sentimento a ser incentivado na educação, uma vez que se reporta à preservação dos saberes de etnicidade e ancestralidade da cultura africana que não podem ser silenciados. Alguns discursos-memórias precisam ser refletidos na escola, "pois indicam sentidos que reafirmam a negritude como uma característica pejorativa: expressões como ovelha negra, mercado negro, a coisa 'tá preta', entre outras" (MELO, 2013, p. $355)$.

À luz das tematizações destacadas, o processo de mediação pedagógica pode colocar em diálogo a historicidade dos grupos étnicos e suas religiosidades, como modos de resistência, para enaltecer as "diferenças" como marcas da heterogeneidade social, cultural e religiosa, a fim de evidenciar os marcadores da pluralidade brasileira. Mediação é entendida aqui nos termos de Martín-Barbero (2018), numa dinâmica que produz conexões de sociabilidades com as diferenças, por meio de uma práxis interativa/educativa resultante dos modos e usos coletivos da comunicação 
humana. Isto é, derivada das práticas de interpelação/constituição dos atores sociais nas suas relações com o mundo.

Assim, a mediação pedagógica nesses termos é desejável não só para construir novos conhecimentos, mas também para permitir "reconhecimentos" históricos: de si e do outro. $\mathrm{Na}$ construção da alteridade os docentes não apenas informam processos, mas podem "formar" pessoas que respeitam a diversidade de culturas, a partir do entendimento de suas práticas de resistências, de fé e de simbologias étnico-raciais.

O próximo passo metodológico seria, então, aproximar o mundo dos deuses africanos do mundo escolar pela via oportuna de algumas interpelações: Como é caracterizado o panteão africano? Quais as suas simbologias de fé? Como as figuras míticas podem auxiliar a abordagem educativa das religiosidades ${ }^{5}$ africanas? De que maneira as histórias em quadrinhos podem colaborar com a proposta de um conhecimento intercultural?

As HQs configuram um gênero linguístico que combina imagens estáticas com elementos textuais na construção de múltiplas narrativas. Quando se unem às questões religiosas, as histórias podem mediar/explorar significativas informações. De acordo com Braga Júnior (2015), no âmbito das religiosidades, as produções simbólico/representacionais dos quadrinhos são aquelas onde a essência religiosa pode ser percebida pelos leitores de modo subjetivo. Nas relações do enredo com as religiosidades, as produções são classificadas como simbólicas (pelos sentidos anunciados através dos sinais gráficos) e representacionais (pela percepção dos valores estereotípicos e arquetípicos das denominações religiosas).

Em razão da configuração indicada, o gênero pode ser utilizado com propósitos educacionais para disseminar valores positivos sobre a diversidade social e religiosa. $\mathrm{O}$ trabalho do quadrinista baiano Hugo Canuto abraça a causa da religiosidade afro-brasileira ao transformar os mitos Iorubás Oxalá, Iemanjá, Exu, Oxum, Iansã e Oxóssi numa coletânea intitulada Contos dos Orixás (The Orixas) na qual as divindades africanas apresentam o visual pop dos super-heróis americanos.

$\mathrm{Na}$ linguagem dos quadrinhos os personagens são carismáticos e guerreiros destacando-se em razão dos valores morais e de ações sobre-humanas por ideais superiores. Dessa forma, reúnem

\footnotetext{
${ }^{5}$ Será que os alunos compreendem os sincretismos dos orixás nas escolas confessionais? Os santos católicos, como as Nossas Senhoras, São Jorge, São João, entre outros, recebem denominações equivalentes nas religiões afro-brasileiras. Mas quais são as razões do sincretismo? Em diversas praias do Brasil existem estátuas de Iemanjá. Por que isso acontece numa nação predominantemente católica? São questões culturais que devem ser mediadas na escola, porque envolvem teses sobre a colonização e a mestiçagem da sociedade brasileira.
} 
habilidades como força, inteligência e ética, sacrificando suas existências em nome da liberdade, fraternidade e justiça sociais. Tais aspectos pressupõem dinâmicas pedagógicas participativas capazes de incitar a colaboração criativa dos estudantes nas relações com os conteúdos didáticopedagógicos.

A produção de analogias entre os orixás e os super-heróis, que originou um roteiro de 120 páginas, exigiu do autor o aprendizado da língua e da cultura Iorubás ${ }^{6}$, com assessoria de sacerdotes do candomblé e acadêmicos. Com esse trabalho, o desenhista ${ }^{7}$ pretende tornar os quadrinhos um “instrumento de empoderamento, reflexão e transformação de percepções sobre o grande legado das civilizações africanas e sua descendência na formação histórica, cultural e espiritual do povo brasileiro".

A coletânea registra a seguinte sinopse: "Em um tempo antigo, deuses e heróis caminharam entre os homens. Travaram batalhas com furor, ensinaram a curar e lidar com a terra, o ferro e o fogo, reinaram e amaram com a mesma intensidade. Alguns desceram do luminoso Orum para realizar seus destinos, enquanto outros nasceram no Aiyê e, pelos grandes feitos, foram elevados a Orixás, marcando para sempre a história de dois continentes.“

Na capa, uma recriação visual de "Os Vingadores" (Avengers 4, 1966), Xangô e Ogum protagonizam a narrativa no lugar dos personagens icônicos Capitão América e Homem de Ferro. No percurso da trama, os leitores são apresentados às outras divindades e aos significados das simbologias que retratam o empoderamento da cultura negra.

\footnotetext{
${ }^{6}$ A civilização do continente africano equivale, atualmente, aos espaços geográficos da Nigéria, Benin e Togo.

${ }^{7}$ Informações obtidas em: <https://hugocanuto.com/gallery/contos-dos-orixas-tales-of-the-orishas/>. Acesso em: $30 \mathrm{de}$ janeiro de 2019.
} 


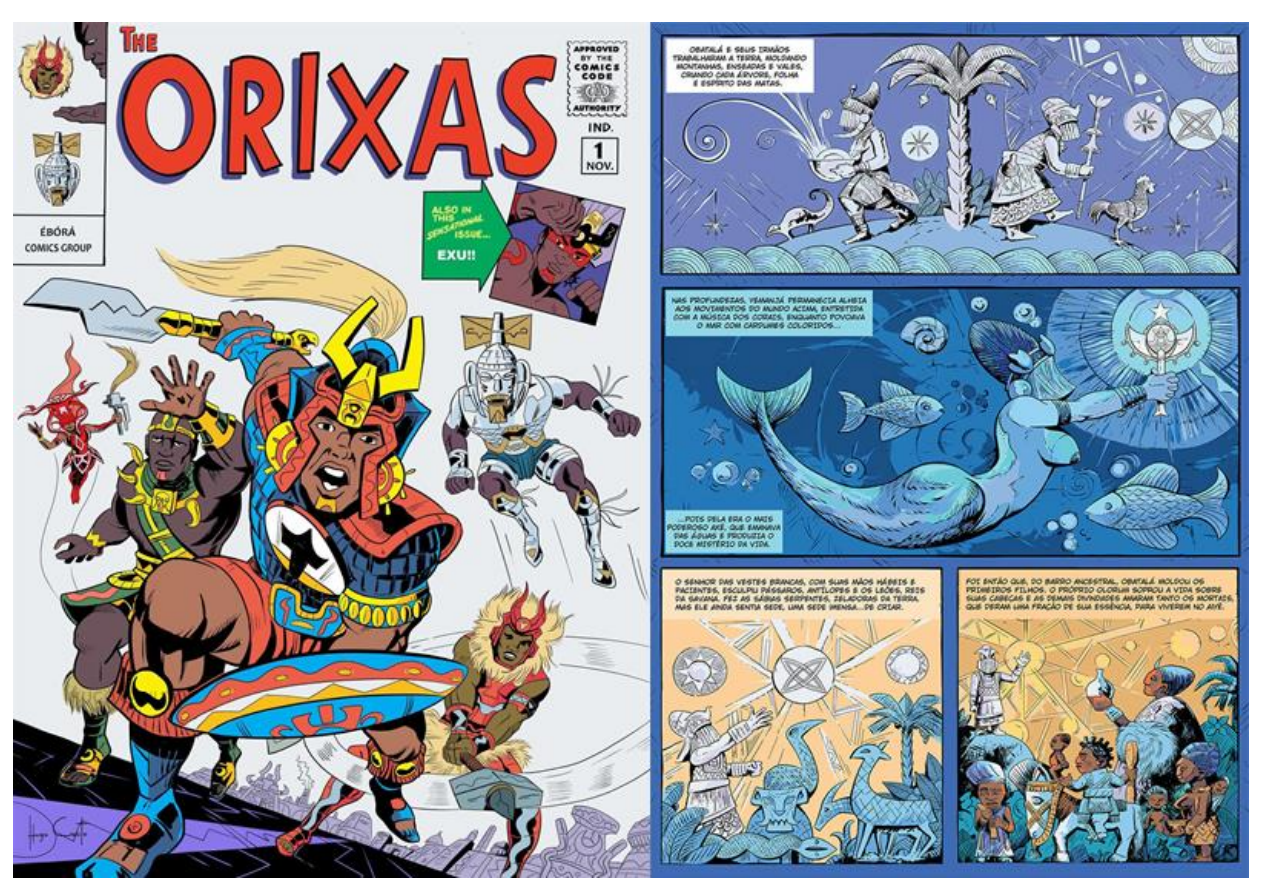

Figura/fonte: <https://hugocanuto.com/gallery/contos-dos-orixas-tales-of-the-orishas/>.

Os orixás super-heróis agregam os aprendizados religiosos aos aprendizados históricoculturais, inspirando pesquisas e levantamentos de informações sobre a religiosidade africana. Outro caminho produtivo na educação é incentivar as criações de HQs dos alunos, a partir dos dispositivos disponibilizados pelo site "Deus no Gibi"§, que democratiza as ferramentas necessárias para a criação de quadrinhos (BRAGA JR, 2015). Através da criatividade é possível instigar a imaginação e a subjetividade em novas representações de temáticas religiosas nas suas intersecções histórico-sociais.

As narrativas podem também suscitar contatos com os religiosos através de visitas e/ou entrevistas com os líderes dos terreiros ou os adeptos. A discussão temática pode ser acompanhada de vídeos ou filmes, bem como de palestras ou exposições fotográficas sobre as religiões, desenvolvidas por grupos de estudantes, profissionais docentes e/ou a comunidade escolar, culminando com a apresentação das produções dos quadrinhos realizadas pelos alunos e suas impressões acerca do estudo.

Elencamos Cinco procedimentos fundamentais para apropriação da metodologia a fim de inspirar o desdobramento de outras ações didático-pedagógicas:

1. Analisar o currículo escolar bem como os livros didáticos de História e os textos de religião para verificar os enfoques históricos concedidos às religiões afro-brasileiras,

\footnotetext{
${ }^{8}$ Disponível em: <https://www.deusnogibi.com.br/>, onde é possível acessar o menu "Crie sua HQ”. Acesso em: 31 de janeiro de 2019.
} 
no que concerne às informações dos grupos e de suas culturas. Utilizar a coletânea Contos dos Orixás como parâmetro de comparação e ponto de partida para as ações pedagógicas posteriores;

2. Discutir a relação do tema "religiosidade afro-brasileira" com a estrutura do espaço escolar, a partir de alguns questionamentos: como a gestão, as familias, a comunidade escolar e seus membros tratam as religiões de matriz africana? Existem praticantes dessas religiões na escola? Existem terreiros de candomblé ou de umbanda nas redondezas? Como seria a representação social desses espaços na temporalidade do passado e do presente?

3. Relacionar leituras e representações acerca dessas crenças para instigar novas percepções sobre elas. Como os deuses africanos poderiam ser ilustrados? Quais características poderiam ser ressaltadas?

4. Criar, em parceria com os docentes de história ou de religião, situações de intercâmbios escolares e de diálogo intercultural para mapear e conhecer as religiões afro-brasileiras da região;

5. Possibilitar aos sujeitos escolares o contato com os lugares sagrados das religiões, através de visitas aos locais de cultos, criando oportunidades para que as imagens dos orixás sejam observadas pelas turmas e professores para inspirar futuras histórias de combate aos preconceitos.

Santos Neto e Silva (2011) afirmam que o recurso pedagógico dos quadrinhos permite "o posicionamento ou reposicionamento dos alunos, mediante uma questão social, pelo estabelecimento de um diálogo e a exposição de outros fundamentos, pontos de vista ou informações" (SANTOS NETO; SILVA, 2011, p. 65). As potencialidades didáticas do gênero são vinculadas à ludicidade $\mathrm{e}$ as propriedades da linguagem visual-verbal como elementos autoexplicativos, cujas contribuições se vinculam às mediações docentes.

\section{CONSIDERAÇÕES FINAIS}

A interculturalidade favorece o reconhecimento da pluralidade cultural da sociedade brasileira possibilitando a criação de propostas educacionais que valorizem e defendam a condição multidiversa. Sob essa ótica, as histórias em quadrinhos podem contribuir no espaço escolar como artefatos de compreensão do mundo direcionados para reflexões críticas sobre a discriminação social ou religiosa que afeta as práticas afro-brasileiras viabilizando percepções do mundo do outro 
a fim de romper com currículos monoculturais que reproduzem estigmas sobre os grupos sociais minoritários.

A coletânea Contos dos Orixás é um aporte metodológico que pode notabilizar a cultura da África na sala de aula por meio do estudo de divindades que se transmutam em super-heróis numa metáfora de empoderamento dos símbolos sagrados. Nesse sentido, os superpoderes fazem apologia à resiliência propiciando o questionamento dos arquétipos eurocêntricos que colonizam os currículos, ao mesmo tempo em que constroem diálogos e saberes à luz das batalhas e conquistas dos deuses afro-brasileiros.

Os enquadramentos lúdicos dos orixás "super-heróis" podem oportunizar o debate das diferenças e das identidades, das vozes e dos saberes dos povos africanos, através de programas interculturais que desestabilizem as pedagogias instituídas para que novos seres humanos sejam formados- dentro e fora dos espaços escolares. 


\section{REFERÊNCIAS}

AIRES, José Luciano Q. A cruz, a espada e os orixás: baixando o santo na sala de aula. In: AIRES, José Luciano Q. et al. (Orgs.). Diversidades étnico raciais \& interdisciplinaridade. Campina Grande: EDUFCG, 2013.

BRAGA JÚNIOR, Amaro Xavier. Configurações das religiosidades no quadrinho brasileiro. In: ; REBLIN, Iuri Andréas. (Orgs.). Religiosidades nas histórias em quadrinhos. Leopoldina: ASPAS, 2015.

CANDAU, Vera Maria. Diferenças culturais, cotidiano escolar e práticas pedagógicas. Currículo sem Fronteiras, v. 11, n. 2, jul./dez. 2011.

CAPUTO, Stela Guedes. Ogan, adósu òjè, ègbónmi e ekedi - O candomblé também está na escola. Mas como? In: CANDAU, Vera Maria; MOREIRA, Antonio Flávio. (Orgs.). Multiculturalismo: diferenças culturais e práticas pedagógicas. Petrópolis: Vozes, 2016.

FLEURI, Reinaldo Matias. Intercultura e educação. Rev. Bras. Educ., Rio de Janeiro, n. 23, maio/ago. 2003.

HALL, Stuart. A identidade cultural na pós-moderni dade. Rio de Janeiro: DP\&A Editora, 2004.

MARTÍN-BARBERO, Jesús. Dos meios às mediações: 3 introduções. Matrizes, São Paulo, v.12, n.1, jan./abr. 2018.

MELO, Josemir C. Resistência, agência e afrocentricidade: a busca por metodologias de ensino e de pesquisa da história e cultura afro-brasileira. In: AIRES, José Luciano Q. et al. (Orgs.). Diversidades étnico raciais \& interdisciplinaridade. Campina Grande: EDUFCG, 2013.

OLIVEIRA, Irene D. Religião e as teias do multiculturalismo. São Paulo: Fonte Editorial, 2015.

. Religiões afro-brasileiras e etnicidade: novas sensibilidades num mundo multicultural. In: OLIVEIRA, Irene D.; REIMER, Ivoni Richter; SOUZA, Sandra D. (Orgs.). Religião, transformações culturais e globalização. Goiânia: PUC Goiás, 2011.

O debate multicultural no âmbito das ciências da religião. Caminhos, Goiânia, v. 6, n. 2, jul./dez. 2008.

SANTOS NETO, Elydio; SILVA, Marta Regina P. (Orgs.). Histórias em quadrinhos e educação: formação e prática docente. São Bernardo do Campo: Universidade Metodista, 2011.

SILVA, Vagner G. Formação e dinâmica das religiões afro-brasileiras. In: SILVA, Eliane M.; BELLOTTI, Karina Kosicki; CAMPOS, Leonildo S. (Orgs.). Religião e Sociedade na América Latina. São Bernardo do Campo: Universidade Metodista de São Paulo, 2010.

VINAGRE SILVA, Marlise. O exercício do poder feminino na tradição étnico-religiosa Iorubá no Brasil: uma estratégia para concretizar direitos em uma sociedade globalizada e desigual. Foz do Iguaçu: CBASS, 2007. (Artigo) 


\section{RESUMO}

Reflexões à luz da interculturalidade sugerem a apropriação dos quadrinhos na educação. A intencionalidade é demonstrar o potencial estético-narrativo do gênero no enfoque das religiões de matriz africana que são silenciadas no espaço escolar. A coletânea Contos dos Orixástorna-se chave de leitura e problematização dos símbolos sagrados dessas culturas religiosas.

Palavras-chave: Educação Intercultural. Religiões Afro-Brasileiras. História em Quadrinhos.

\section{ORIXÁS ARE SUPERHEROES: COMIC MEDIATIONS IN THE CONTEXT OF INTERCULTURAL EDUCATION}

\section{ABSTRACT}

Reflections in the light of interculturality suggest the appropriation of comics in education. The intentionality is to demonstrate the aesthetic-narrative potential of the genre in the focus of religions of African matrix that are silenced in the school space. The collection Tales of the Orixas becomes key of reading and problematization of the sacred symbols of these religious cultures.

Keywords: Intercultural education. Afro-brazilian religions. Comics.

\section{ORIXÁS SON SUPER-HÉROES: LA MEDIACIÓN DE LOS COMICS EN EL CONTEXTO DE LA EDUCACIÓN INTERCULTURAL}

\section{RESUMEN}

Las reflexiones a la luz de la interculturalidad sugieren la apropiación de los cómics en la educación. La intencionalidad es demostrar el potencial estético-narrativo del género en el enfoque de las religiones de matriz africana que son silenciadas en el espacio escolar. La colección Cuentos de los Orixás se convierte en clave de lectura y problematización de los símbolos sagrados de las culturas religiosas.

Palabras clave: Educación Intercultural. Religiones Afro-Brasileñas. Historia del cómic.

Submetido em: 13 defevereiro de 2019

Aprovado em: 30 de abril de 2019 